\title{
Optimal Devaluations
}

\section{CONSTANTINO HEVIA and JUAN PABLO NICOLINI*}

The paper analyzes optimal policy in a simple small open economy model with price setting frictions. In particular, the paper studies the optimal response of the nominal exchange rate following a terms-of-trade shock. The paper departs from the New Keynesian (NK) literature in that it explicitly models internationally traded commodities as intermediate inputs in the production of local final goods and assume that the small open economy takes this price as given. This modification is not only in line with the long standing tradition of small open economy models, but also changes the optimal movements in the exchange rate. In contrast with the recent Small Open Economy NK literature, the model in this paper is able to reproduce the comovement between the nominal exchange rate and the price of exports, as it has been documented in the commodity currencies literature. Although the paper shows that there are preferences for which price stability is optimal even without flexible fiscal instruments, the model suggests that more attention should be given to the coordination between monetary and fiscal policy (taxes) in small open economies that are heavily dependent on exports of commodities. The model the paper proposes is a useful framework to study fear of floating. [JEL E52, F41, H21] IMF Economic Review (2013) 61, 22-51. doi:10.1057/imfer.2013.2;

published online 2 April 2013

\footnotetext{
*Constantino Hevia received his Ph.D. in Economics from the University of Chicago. Prior to joining the Department of Economics at Universidad Torcuato di Tella, he worked at the World Bank, where he is currently on leave. Juan Pablo Nicolini is a Senior Economist at the Federal Reserve Bank of Minneapolis and Professor of Economics at Universidad Torcuato di Tella. He earned his Ph.D. in Economics from the University of Chicago. This paper started after a very entertaining discussion with Eduardo Levy Yeyati and Ernesto Schargrodsky, and grew out of many conversations with Pedro Teles. The authors also thank Raphael Bergoeing, Patrick Kehoe, Tomasso Monacelli, Andres Neumeyer, and Rodolfo Manuelli for comments. Finally, the authors want to thank Charles Engle for a very clarifying discussion. But all errors are the authors'.
} 
he purpose of this paper is to study the optimal response of monetary and exchange rate policy to a change in the price of a commodity that a small open economy actively trades in international markets. The question of determining optimal policy is very important for many economies in the world. Indeed, commodity prices are very volatile, and in many cases, exports of commodities are a sizable fraction of foreign trade. In Figure 1, we plot monthly data on prices for a set of commodities during the period January 2000-December 2012. The prices are expressed in constant dollars and normalized to be 100 in January 2000. In Table 1 we report the principal commodity exports for a selection of small open economies and their shares in total goods exports, total exports, and over GDP. ${ }^{1}$

Concern regarding shocks to commodity prices runs very high in the political agenda of these countries. For small open economies (say, Chile), a drop in the exportable commodity price (copper) is seen as recessionary; the same happens following an increase in the price of the importable commodity (oil). ${ }^{2}$ It is precisely to hedge against this uncertainty that, in recent years, countries in which the government either owns or taxes the firms that produce a particular commodity, like Norway (oil) and Chile (copper), passed legislation forcing the treasury to save in foreign assets during periods when the commodity prices are "high," in order to be able to spend more during times in which the prices are "low." Although clearly the volatility of international commodity prices can give rise to fiscal policies like the one just described, less clear are its implications, if any, regarding monetary and exchange rate policy. In small open economies, movements in the nominal exchange rate are important shock absorbers. In a world with fully flexible prices, this feature should not be important. But in the presence of nominal rigidities, as emphasized in the new open economy macroeconomics literature, shocks to the terms of trade could lead to inefficient real effects. That literature, however, has so far ignored the effects of commodity price shocks. This is the main theme of our paper.

The question we address is a central one for policy design in small open economies. For example, both Chile and Norway have explicitly adopted an inflation-targeting policy. This means that the central bank defines an inflation rate on the consumer price index as its main policy objective. Therefore, the central bank abstains from foreign exchange interventions, and the nominal exchange rate is fully market determined. It turns out that the resulting volatility of the nominal exchange rate is very high and that it moves negatively with the international price of the exportable commodity in small open economies that follow inflation targeting. ${ }^{3}$ Figure 2 depicts the

\footnotetext{
${ }^{1}$ Total imports of commodities can also be large, but they are not as concentrated in a few goods. That is why we do not report a table similar to Table 1 for imports.

${ }^{2}$ Chile imported over 90 percent of the oil consumed during the last 10 years.

${ }^{3}$ To the extent that these countries succeed in stabilizing inflation, the nominal exchange rate volatility translates into real exchange rate volatility.
} 
Figure 1. Evolution of Selected Commodity Prices Measured in January 2000 U.S. Dollars

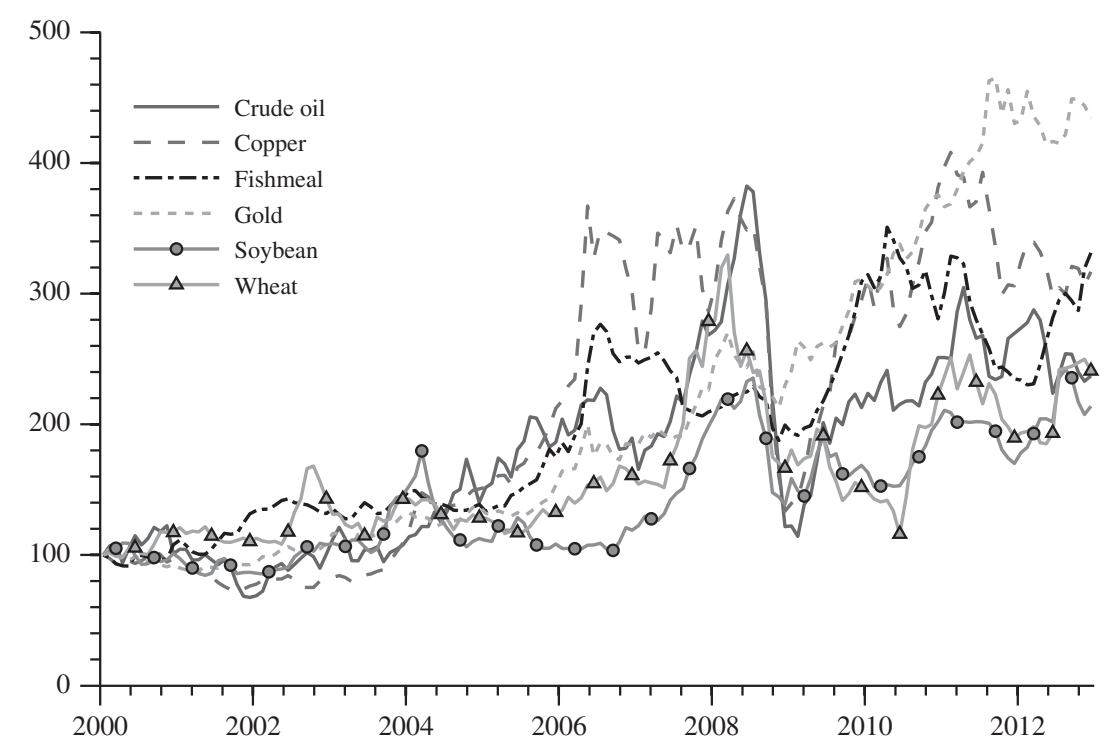

Series have been normalized to 100 in January 2000.

nominal exchange rate and the dollar price of the main exportable commodity for Chile and Norway as deviations from trend. The shocks are very large. In Table 2, we report several moments for these variables. The table makes clear that the volatilities of these shocks are large, as are their correlations. In the text, we focus on Chile and Norway, since identifying the main exportable commodity is easy. In the Appendix we show that these facts are robust, by providing evidence for other countries in Table 1. Further evidence is provided by the commodity currency literature (Chen and Rogoff, 2003).

The current literature that studies optimal monetary policy with price frictions in small open economies has totally ignored commodities. Therefore, the literature is unable to reproduce these facts and provides no useful guide to the policy questions that we study in this paper.

It is precisely because of the high volatilities shown in the tables and figures that the institutional frameworks allow central banks to deviate from the pure inflation-targeting policy under "special circumstances," even in explicit inflation-targeting regimes. The central bank of Chile did so in April 2008 and announced a program for buying international reserves (for an amount close to 40 percent of the existing stock) after the nominal exchange rate went from over 750 pesos per dollar in March 2003 to below 450 in March 2008. The program was suspended with only 70 percent of the announced purchases completed in September 2008, once the exchange rate jumped back to around 650 pesos. A new program to buy reserves was 
Table 1. Principal Commodity Exports in Selected Countries

\begin{tabular}{|c|c|c|c|c|c|c|c|}
\hline \multirow[b]{2}{*}{ Panel A } & \multicolumn{3}{|c|}{ Principal Commodity Exports (Monthly Averages since Jan 2000) } & \multicolumn{4}{|c|}{ Share in Goods Exports } \\
\hline & $\mathrm{C} 1$ & $\mathrm{C} 2$ & $\mathrm{C} 3$ & $\mathrm{C} 1$ & $\mathrm{C} 2$ & $\mathrm{C} 3$ & Total \\
\hline Argentina & Soybean and products & Petroleum and products & Wheat & 23 & 9 & 4 & 36 \\
\hline Australia & Coal & Iron ore & Gold & 14 & 9 & 5 & 28 \\
\hline Brazil & Soybean and products & Petroleum and products & Iron oxides & 9 & 8 & 7 & 24 \\
\hline Chile & Copper & Marine products & - & 45 & 7 & - & 52 \\
\hline Iceland & Marine products & Aluminium & - & 53 & 25 & - & 78 \\
\hline New Zealand & Dairy produce & Meat and edible offal & Wood and products & 19 & 13 & 7 & 39 \\
\hline Norway & Petroleum and products & Marine products & - & 57 & 5 & - & 62 \\
\hline Peru & Copper & Gold & Marine products & 20 & 19 & 8 & 47 \\
\hline
\end{tabular}

Aggregate Shares

\begin{tabular}{|c|c|c|c|}
\hline Panel B & Goods/Total Exports & Total Exports/GDP & Commodities/GDP \\
\hline Argentina & 87 & 22 & 6.9 \\
\hline Australia & 78 & 20 & 4.4 \\
\hline Chile & 83 & 39 & 16.8 \\
\hline Iceland & 65 & 37 & 18.8 \\
\hline New Zealand & 74 & 30 & 8.7 \\
\hline Norway & 76 & 44 & 20.7 \\
\hline Peru & 87 & 22 & 9.0 \\
\hline
\end{tabular}

Sources: National statistics agencies. Columns labeled "C1-C3" report the most important commodities and their shares in total exports of goods. Column labeled "Total" reports the share of the three principal commodities on total good exports. Shares are reported in percentage terms. Commodity exports data are monthly, and the last observation varies by country: Argentina, Jan 2000-Jun 2010; Australia, Jan 2000-Oct 2010; Brazil, Jan 2000-Oct 2010; Chile, Jan 2000-Nov 2010; Iceland, Jan 2000-Oct 2010; New Zealand, Jan 2000-Oct 2010; Norway, Jan 2000-Oct 2010; and Peru, Jan 2000-Sep 2010. 
Figure 2. Evolution of the Exchange Rate (Local Currency Per U.S. Dollar) and the Price of the Main Commodity Exported by Chile and Norway, all Expressed as a Percentage Deviation from Trend and at a Quarterly Frequency
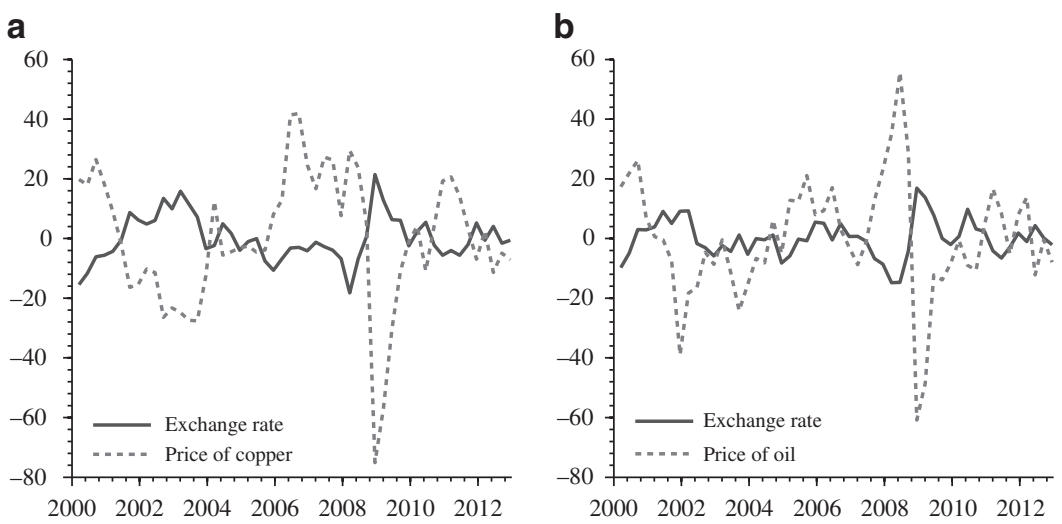

To obtain the cyclical components, the series are first logged and then HP-filtered with a smoothing parameter of 1600. (a) Chile; (b) Norway.

Table 2. Exchange Rates and Commodity Prices in Chile and Norway

\begin{tabular}{|c|c|c|c|c|}
\hline & \multicolumn{2}{|c|}{ In U.S. Dollars } & \multicolumn{2}{|c|}{ In Euros } \\
\hline & Standard Deviation & Correlation & Standard Deviation & Correlation \\
\hline \multicolumn{5}{|l|}{ Chile } \\
\hline Exchange rate & $7.7(0.9)$ & $-0.82(0.06)$ & $7.6(0.8)$ & $-0.76(0.04)$ \\
\hline Price of copper & $22.2(3.6)$ & & $21.9(3.4)$ & \\
\hline \multicolumn{5}{|l|}{ Norway } \\
\hline Exchange rate & $6.3(1.0)$ & $-0.68(0.17)$ & $3.9(0.6)$ & $-0.56(0.20)$ \\
\hline Price of oil & $19.6(3.8)$ & & $18.2(3.0)$ & \\
\hline
\end{tabular}

This table shows summary statistics of nominal exchange rate and commodity prices measured in January 2000 U.S. dollars. Data are at a quarterly frequency and transformed as percentage deviations from trend. Deviations from trend are computed by HP-filtering the logarithm of each series with a smoothing parameter of 1,600. GMM-based standard errors are reported in parentheses.

announced in January 2011 with a total amount over 40 percent of the existing stock. At that time, the exchange rate was around 475 pesos per dollar. The exchange rate in December 2012 was again around 475 pesos per dollar. The justification used by the board of the central bank of Chile was that "the international economy presents an unusual state, characterized by high commodity prices, low interest rates, slow recovery of the developed economies, and depreciation of the U.S. dollar." ${ }^{4}$

${ }^{4}$ The statement can be found at Estrategia Online, April 1, 2011, www.estrategia.cl/ detalle_noticia.php?cod $=36317$. The translation to English has been made by the authors. 
Is this an optimal policy in a small open economy facing large shocks to commodity prices? The model we analyze in this paper builds from the existing literature and provides a step toward providing an answer to that question.

Following the seminal work of Obstfeld and $\operatorname{Rogoff}(1995,1996)$, there has been growing interest in studying optimal policy in open economies with frictions in the setting of prices or wages. A branch of the literature, like Obstfeld and Rogoff (2000) and Engel (2001), focuses on the two-country case. $^{5}$ This literature emphasizes the relationship between the strategic interactions in two-country models and optimal exchange rate policy, and in most cases, it focuses on the flexible vs. fixed exchange rate regimes debate. Gali and Monacelli (2005) specifically consider the case of the small open economies; several other papers have followed, like Faia and Monacelli (2008) and de Paoli (2009).

The main innovation of our paper is to explicitly model commodities as intermediate goods in production, using a model similar in spirit to the one used by Burstein, Neves, and Rebelo (2003) and Burstein, Eichenbaum, and Rebelo (2007). ${ }^{6}$ Following the tradition on small open economy models, the international price of these commodities is exogenous to the economy we consider. In the NK small open economy models, only domestic inputstypically labor - enter into the production function of domestic final goods. The final goods are produced by local monopolists and are traded internationally. In our model, domestic inputs and traded commodities enter the production function of a continuum of intermediate goods produced by local monopolists. These intermediate goods, in turn, are used in the production of a final good that can be traded internationally, as in the previous models.

This is the obvious modification to make, given the motivation of the paper: to study optimal monetary and exchange rate policy in the presence of shocks to commodity prices. But it is also important, as we will clearly demonstrate in the paper, for two other reasons. First, in the existing models, an increase in the price of importables is, contrary to the concerns mentioned above, expansionary. The reason is that a reduction in the international relative price of local final goods implies, via a substitution effect in preferences, an increase in world - and local-demand for the local composite good, which in turn increases local production. On the contrary, in our model, when the increase is on the price of the intermediate importable - relative to the intermediate exportable - the units of labor

\footnotetext{
${ }^{5}$ See also Corsetti and Pesenti (2001, 2005), Devereux and Engel (2003), Benigno and Benigno (2003), Duarte and Obstfeld (2008), Ferrero (2005), and Adao, Correia, and Teles (2009), among many others.

${ }^{6}$ In our model, commodities are intermediate inputs that are traded internationally in perfectly competitive markets. This assumption, very common in the small open economy models in the 1970s and 1980s, has been dropped in the New Keynesian small open economy literature.
} 
required to import one unit of the intermediate importable increases and is therefore contractionary. Second, in the model without traded commodities, a shock to the terms of trade does not change local costs, so it does not interact in an interesting way with the domestic price frictions. Given the emphasis of this paper, this is a key distinction.

On the methodological front, we also depart from the literature in that we consider distorting fiscal instruments, as in Lucas and Stokey (1983), Chari, Christiano, and Kehoe (1996), and Correia, Nicolini, and Teles (2008). This approach has the advantage of making explicit all the existing distortions in the economy. The analysis thus provides a minimal set of monetary and fiscal instruments required to achieve the second best allocation. One could then use the model to evaluate the welfare cost of imposing restrictions on the available instruments. Indeed, it has become standard in the NK literature to assume that while monetary policy and exchange rate policy are flexible, in the sense that they can be made time and state dependent, fiscal policy is not. The model of the paper can easily be used to evaluate optimal policy with restrictions on the set of instruments.

We study a representative agent economy with final goods produced using a continuum of nontradable intermediate goods, which, in turn, are produced by monopolistically competitive firms - so firms have power to set prices - and tradable commodities - so we can analyze the optimal policy response following terms-of-trade shocks. Intermediate goods are produced using domestic labor ${ }^{7}$ and two tradable commodities (one importable and one exportable). The exportable commodity is produced by perfectly competitive firms that take the international price as given and use labor and a nontradable input in fixed supply, which can be broadly interpreted as "land." 8 The price of the importable commodity is also given to the country. We follow the literature and assume a Calvo-type price rigidity, in which only a randomly selected group of intermediate goods firms are allowed to change prices in any given period. We also follow the tradition of the recent NK literature and assume a cashless economy where currency only plays the role of a numeraire.

The fiscal policy instruments that we consider are labor income taxes, dividend taxes, export and import tariffs on final goods, and a tax on the returns on foreign assets, which can be interpreted as a tax on capital flows. ${ }^{9}$ We also allow the government to issue state-contingent bonds in domestic and foreign currency. We abstract from the question of the best intermediate target for monetary policy and also from the question of implementability. We characterize sequences of nominal exchange rates, $\left\{S_{t}\right\}_{t=0}^{\infty}$, that are

\footnotetext{
${ }^{7} \mathrm{We}$ interpret labor broadly, including all services that are nontradable and that are essential to production.

${ }^{8}$ This input should be interpreted more broadly than actual land. It could represent oil or copper reserves in the case of exhaustible resources.

${ }^{9}$ This latter tax is equivalent to a time-varying consumption tax, as the one used by Adao, Correia, and Teles (2009).
} 
consistent with the optimal allocation, but we abstract from the bigger question of how to implement that allocation. Implicit in the solution of the optimal policy is a sequence of nominal interest rates, $\left\{R_{t}\right\}_{t=0}^{\infty}$, that is consistent with the allocation. It is well known, however, that while exchange rate rules implement a unique allocation, interest rate rules lead to global indeterminacy. As it is standard in Ramsey analyses, we also abstract from time inconsistency and assume full commitment. Thus, whichever role the exchange rate can have in fostering good - or bad! - reputation will be absent in this analysis.

We first show, in Section I, how the introduction of commodities implies that domestic costs interact with commodity prices and changes the transmission mechanism of nominal exchange rate movements. We also show that the model can theoretically be consistent with the evidence in Table 2 in countries that follow inflation targeting. Movements in the exchange rate become key to stabilize costs and, therefore, prices.

In Section II, we solve for the Ramsey allocation. We show that if taxes can be flexible, price stability is optimal, as in Gali and Monacelli (2005). Thus, their policy implication survives in a different model, which can potentially replicate the moments in Table 2 and where the transmission mechanism of exchange rate movements is very different. ${ }^{10}$ The reason is that in these models with price frictions, price stability implies production efficiency, as will become clear in the discussion that follows. Production efficiency is a feature of the optimal allocation in many environments. We should emphasize, though, that this result hinges critically on the assumption of flexible fiscal policy. That is, the solution will, in general, require the taxes (labor income taxes and capital controls) to be state and time dependent. But we also show that there is a particular case where the optimal solution involves tax rates that are constant. That is, in this particular case, the Ramsey government will choose to have taxes that are constant over time and states, even if they could be flexible. That particular case, as it turns out, involves the preferences that are widely used in the NK literature (Gali and Monacelli, 2005; Farhi, Gopinath, and Itskhoki, 2011; among many others). ${ }^{11}$ These preferences exhibit constant elasticities for labor and aggregate consumption. Interestingly enough, this result does not depend on the functional forms assumed for the two sectors in the economy. The only requirement is that production functions exhibit constant returns to scale. $^{12}$ Thus, in this case, the model justifies a policy that stabilizes prices

\footnotetext{
${ }^{10}$ It should be noted, however, that we only consider the case of domestic producer price frictions. Allowing for local currency price frictions, or adding wage frictions on top of the price frictions, would change the implications of this model. In the jargon of the New Keynesian literature, the "divine coincidence" falls apart in those cases. We leave the analysis of these cases for future research.

${ }^{11}$ Similar results have been found for closed economies (Zhu, 1992).

${ }^{12}$ This feature is reminiscent of the celebrated homogeneous taxation result of Diamond and Mirrlees (1971), as pointed out in Correia, Nicolini, and Teles (2008).
} 
even if the nominal exchange rate is subject to very large fluctuations and taxes cannot be made flexible. Put differently, the "divine coincidence" holds even with constant taxes, as long as preferences can be well described by the isoelastic form.

Finally, in Section III, we show that a quantitative version of the model can reproduce the behavior of the nominal exchange rate in Chile and Norway (as depicted in Figure 2 and Table 2), as long as the parameters governing the input-output matrix satisfy certain properties.

\section{The Model}

The model is composed of a small open economy, which we call home, and the rest of the world. Time is discrete and denoted by $t=0,1,2, \ldots, \infty$. Two final goods can be internationally traded, one of them produced at home and the other produced in the rest of the world. The home economy faces a downward-sloping demand for the final good it produces but is unable to affect any other international price. International trade takes place in two commodities that are used in the production of intermediate goods. Home is inhabited by households, the government, competitive firms that produce the final good, competitive firms that produce one of the tradable commodities, and a continuum of firms that produce differentiated intermediate goods.

\section{Households}

A representative household has preferences over contingent sequences of two final consumption goods, $C_{t}^{h}$ and $C_{t}^{f}$, and labor $N_{t}$. The utility function is weakly separable between the final consumption goods and labor and is represented by

$$
E_{0} \sum_{t=0}^{\infty} \beta^{t} U\left(C_{t}, N_{t}\right),
$$

where $0<\beta<1$ is a discount factor, $C_{t}=H\left(C_{t}^{h}, C_{t}^{f}\right)$ is a function homogeneous of degree one and increasing in each argument, and $U(C, N)$ is increasing in the first argument, decreasing in the second, and concave.

Financial markets are complete. We let $B_{t, t+1}$ and $B_{t, t+1}^{*}$ denote oneperiod discount bonds denominated in domestic and foreign currency, respectively. These are bonds issued at period $t$ that pay one unit of the corresponding currency at period $t+1$ on a particular state of the world and zero otherwise.

The household's budget constraint is given by

$$
\begin{aligned}
& P_{t}^{h} C_{t}^{h}+P_{t}^{f} C_{t}^{f}+E_{t}\left[Q_{t, t+1} B_{t, t+1}+S_{t} Q_{t, t+1}^{*} \tilde{B}_{t, t+1}^{*}\right] \\
& \leq W_{t}\left(1-\tau_{t}^{n}\right) N_{t}+B_{t-1, t}+S_{t} \frac{\tilde{B}_{t-1, t}^{*}}{1+\tau_{t}^{*}}
\end{aligned}
$$


where $S_{t}$ is the nominal exchange rate between domestic and foreign currency, $W_{t}$ is the nominal wage rate, $\tau_{t}^{n}$ is a labor income tax, $\tau_{t}^{*}$ is a tax on the return of foreign-denominated bonds (a tax on capital flows), and $Q_{t, t+1}$ is the domestic currency price of the one-period contingent domestic bond normalized by the probability of the state of the economy in period $t+1$ conditional on the state in period $t$. Likewise, $Q_{t, t+1}^{*}$ is the normalized foreign currency price of the foreign bond. ${ }^{13}$ In this constraint, we assume that dividends are fully taxed and that consumption taxes are zero (we explain these choices below).

Using the budget constraint at periods $t$ and $t+1$ and rearranging gives the no-arbitrage condition between domestic and foreign bonds:

$$
Q_{t, t+1}=Q_{t, t+1}^{*}\left(1+\tau_{t+1}^{*}\right) \frac{S_{t}}{S_{t+1}} .
$$

Working with the present value budget constraint is convenient. To that end, for any $k>0$, we let $Q_{t, t+k}=Q_{t, t+1} Q_{t+1, t+2} \ldots Q_{t+k-1, t+k}$ be the price of one unit of domestic currency at a particular history of shocks in period $t+k$ in terms of domestic currency in period $t$; an analogous definition holds for $Q_{t, t+k}^{*}$. Iterating forward on Equation (2) and imposing the no-Ponzi condition $\lim _{t \rightarrow \infty} E_{0}\left[Q_{0, t} B_{t}+S_{t} Q_{0, t}^{*} \tilde{B}_{t}^{*}\right] \geq 0$ gives

$$
E_{0} \sum_{t=0}^{\infty} Q_{0, t}\left(P_{t}^{h} C_{t}^{h}+P_{t}^{f} C_{t}^{f}-W_{t}\left(1-\tau_{t}^{n}\right) N_{t}\right) \leq 0
$$

where we have assumed that initial financial wealth is zero, or $B_{-1,0}=\tilde{B}_{-1,0}^{*}=0$.

The household maximizes Equation (1) subject to Equation (4). The optimality conditions are given by

$$
\begin{aligned}
& \frac{H_{C^{h}}\left(C_{t}^{h}, C_{t}^{f}\right)}{H_{C^{f}}\left(C_{t}^{h}, C_{t}^{f}\right)}=\frac{P_{t}^{h}}{P_{t}^{f}} \\
& \frac{U_{C}\left(C_{t}, N_{t}\right) H_{C^{h}}\left(C_{t}^{h}, C_{t}^{f}\right)}{-U_{N}\left(C_{t}, N_{t}\right)}=\frac{P_{t}^{h}}{W_{t}\left(1-\tau_{t}^{n}\right)} \\
& \frac{U_{C}\left(C_{t}, N_{t}\right) H_{C^{h}}\left(C_{t}^{h}, C_{t}^{f}\right)}{P_{t}^{h}}=\beta \frac{1}{Q_{t, t+1}} \frac{U_{C}\left(C_{t+1}, N_{t+1}\right) H_{C^{h}}\left(C_{t}^{h}, C_{t}^{f}\right)}{P_{t+1}^{h}} .
\end{aligned}
$$

${ }^{13} \mathrm{We}$ use the notation $\tilde{B}_{t, t+1}^{*}$ instead of simply $B_{t, t+1}^{*}$ to distinguish foreign bonds held by the household sector from foreign bonds held by the aggregate economy. 


\section{Government}

The government sets monetary and fiscal policy and raises taxes to pay for exogenous consumption of the home final good, $G_{t}^{h .14}$ Monetary policy consists of rules for either the nominal interest rate $R_{t}$ or the nominal exchange rate $S_{t}$. Fiscal policy consists of labor taxes $\tau_{t}^{n}$; export and import taxes on foreign goods, $\tau_{t}^{h}$ and $\tau_{t}^{f}$, respectively; taxes on returns of foreign assets $\tau_{t}^{*}$; and dividend taxes $\tau_{t}^{d}$. The two sources of pure rents in the model are the dividends of intermediate good firms and the profits of commodity producers - equivalently, one can think of the latter as a tax on the rents associated with a fixed factor of production. Throughout the paper, we assume that all rents are fully taxed so that $\tau_{t}^{d}=1$ for all $t$. The reason for this assumption is that if pure rents are not fully taxed, the Ramsey government will use other instruments to partially tax those rents. We deliberately abstract from those effects in the optimal policy problem. Note, in addition, that there are no consumption taxes. This assumption is without loss of generality because, in the current setting, consumption taxes are a redundant instrument: anything that can be done with consumption taxes can also be done with appropriately chosen labor taxes and taxes on capital flows.

\section{Final Good Firms}

Perfectly competitive firms produce the domestic final good $Y_{t}^{h}$ by combining a continuum of nontradable intermediate goods indexed by $i \in(0,1)$ using the technology

$$
Y_{t}^{h}=\left[\int_{0}^{1} y_{i t}^{\frac{\theta-1}{\theta}} d i\right]^{\frac{\theta}{\theta-1}},
$$

where $\theta>1$ is the elasticity of substitution between each pair of intermediate goods. Taking as given the final good price, $P_{t}^{h}$, and the prices of each individual variety of intermediate goods, $P_{i t}^{h}$ for $i \in(0,1)$, the firm's problem implies the cost minimization condition

$$
y_{i t}=Y_{t}^{h}\left(\frac{P_{i t}^{h}}{P_{t}^{h}}\right)^{-\theta}
$$

for all $i \in(0,1)$. Integrating this condition over all varieties and using the production function gives a price index relating the final good price and the prices of the individual varieties,

$$
P_{t}^{h}=\left(\int_{0}^{1} P_{i t}^{h 1-\theta} d i\right)^{\frac{1}{1-\theta}} .
$$

\footnotetext{
${ }^{14}$ It is straightforward to also let the government consume foreign goods.
} 


\section{Commodities Sector}

Two tradable commodities, denoted by $x$ and $z$, are used as inputs in the production of intermediate goods. The home economy, however, is able to produce only the commodity $x$; the commodity $z$ must be imported. We denote by $P_{t}^{x}$ and $P_{t}^{z}$ the local currency prices of the commodities.

Total output of commodity $x$, denoted as $X_{t}$, is produced according to the technology

$$
X_{t}=A_{t}\left(n_{t}^{x}\right)^{\rho},
$$

where $n_{t}^{x}$ is labor, $A_{t}$ is the level of productivity, and $0<\rho \leq 1$. Implicit in this technology is the assumption of a fixed factor of production (when $\rho<1$ ), which we broadly interpret as land. Profit maximization then requires

$$
\rho P_{t}^{x} A_{t}\left(n_{t}^{x}\right)^{\rho-1}=W_{t} .
$$

Because the two commodities can be freely traded, the law of one price holds:

$$
\begin{aligned}
& P_{t}^{x}=S_{t} P_{t}^{x *} \\
& P_{t}^{z}=S_{t} P_{t}^{z *},
\end{aligned}
$$

where $P_{t}^{x_{*}}$ and $P_{t}^{z *}$ denote the foreign currency prices of the $x$ and $z$ commodities. ${ }^{15}$

\section{Intermediate Good Firms}

Each intermediate good $i \in(0,1)$ is produced by a monopolistic competitive firm which uses labor and the two tradable commodities with the technology

$$
y_{i t}=\bar{\eta} Z_{t} x_{i t}^{\eta_{1}} z_{i t}^{\eta_{2}}\left(n_{i t}^{y}\right)^{\eta_{3}},
$$

where $x_{i t}$ and $z_{i t}$ are the demand for commodities, $n_{i t}^{v}$ is labor, $Z_{t}$ denotes the level of productivity, $\eta_{j} \geq 0$ for $j=1,2,3, \sum_{j=1}^{3} \eta_{j}=1$, and $\bar{\eta}=\eta_{1}^{-\eta_{1}} \eta_{2}^{-\eta_{2}} \eta_{3}^{-\eta_{3}}{ }^{16}$

The associated nominal marginal cost function is common across intermediate good firms and given by

$$
M C_{t}=\frac{\left(P_{t}^{x}\right)^{\eta_{1}}\left(P_{t}^{z}\right)^{\eta_{2}} W_{t}^{\eta_{3}}}{Z_{t}}
$$

\footnotetext{
${ }^{15} \mathrm{We}$ could also allow for tariffs on the intermediate inputs. As will become clear, however, these tariffs are redundant instruments in this environment.

${ }^{16}$ Our results generalize to any constant returns to scale technology.
} 
Using Equations (11) and (12), the nominal marginal cost can be written as $M C_{t}=S_{t} M C_{t}^{*}$, where $M C_{t}^{*}$, the marginal cost measured in foreign currency, is given by

$$
M C_{t}^{*}=\frac{\left(P_{t}^{x *}\right)^{1-\eta_{2}}\left(P_{t}^{z *}\right)^{\eta_{2}}\left(\rho A_{t}\left(n_{t}^{x}\right)^{\rho-1}\right)^{\eta_{3}}}{Z_{t}} .
$$

That is, the marginal cost in foreign currency depends on the international commodity prices, on technological factors, and on the equilibrium allocation of labor in the commodities sector.

In addition, cost minimization implies that final intermediate good firms choose the same ratio of inputs,

$$
\begin{aligned}
& \frac{x_{i t}}{n_{i t}^{y}}=\frac{\eta_{1}}{\eta_{3}} \rho A_{t}\left(n_{t}^{x}\right)^{\rho-1} \\
& \frac{z_{i t}}{n_{i t}^{y}}=\frac{\eta_{2}}{\eta_{3}} \frac{P_{t}^{x *}}{P_{t}^{z *}} \rho A_{t}\left(n_{t}^{x}\right)^{\rho-1} \quad \text { for all } i \in(0,1),
\end{aligned}
$$

where we have used Equation (11) in the second equation.

Introducing Equation (14) into the production function gives

$$
y_{i t}=n_{i t}^{y} \frac{Z_{t}}{\eta_{3}}\left(\rho A_{t}\left(n_{t}^{x}\right)^{\rho-1}\right)^{1-\eta_{3}}\left(P_{t}^{x *}\right)^{\eta_{2}}\left(P_{t}^{z *}\right)^{-\eta_{2}} .
$$

Each monopolist $i \in(0,1)$ faces the downward-sloping demand curve represented by equation (8). We follow the standard tradition in the NK literature and impose Calvo price rigidity. Namely, in each period, intermediate good firms are able to reoptimize nominal prices with a constant probability $0<\alpha<1$. Those that get the chance to set a new price will set it according to

$$
p_{t}^{h}=\frac{\theta}{\theta-1} E_{t} \sum_{j=0}^{\infty} \chi_{t, j} \frac{\left(P_{t+j}^{x}\right)^{\eta_{1}}\left(P_{t+j}^{z}\right)^{\eta_{2}} W_{t+j}^{\eta_{3}}}{Z_{t+j}},
$$

where

$$
\chi_{t, j}=\frac{\alpha^{j} Q_{t, t+j}\left(P_{t+j}^{h}\right)^{\theta} Y_{t+j}^{h}}{E_{t} \sum_{j=0}^{\infty} \alpha^{j} Q_{t, t+j}\left(P_{t+j}^{h}\right)^{\theta} Y_{t+j}^{h}} .
$$

The price level in Equation (9) can be written as

$$
P_{t}^{h}=\left[(1-\alpha)\left(p_{t}^{h}\right)^{1-\theta}+\alpha\left(P_{t-1}^{h}\right)^{1-\theta}\right]^{\frac{1}{1-\theta}} .
$$




\section{Implications of Price Stability}

A monetary policy that successfully stabilizes the domestic price of the final good must stabilize the marginal cost. Indeed, note that if

$$
\frac{\left(P_{t}^{x}\right)^{\eta_{1}}\left(P_{t}^{z}\right)^{\eta_{2}} W_{t}^{\eta_{3}}}{Z_{t}}=M C \text { for all } t
$$

then

$$
p_{t}^{h}=M C \frac{\theta}{\theta-1} E_{t} \sum_{j=0}^{\infty} \chi_{t, j}=M C \frac{\theta}{\theta-1} \text { for all } t .
$$

But

$$
M C=S_{t} \frac{\left(P_{t}^{x *}\right)^{1-\eta_{2}}\left(P_{t}^{z *}\right)^{\eta_{2}}\left(\rho A_{t}\left(n_{t}^{x}\right)^{\rho-1}\right)^{\eta_{3}}}{Z_{t}},
$$

so stabilizing marginal costs implies that

$$
S_{t}=\frac{1}{M C} \frac{Z_{t}}{\left(P_{t}^{x *}\right)^{1-\eta_{2}}\left(P_{t}^{z *}\right)^{\eta_{2}}\left(\rho A_{t}\left(n_{t}^{x}\right)^{\rho-1}\right)^{\eta_{3}}} .
$$

Thus, the volatility of the nominal exchange rate depends on the volatility of the exogenous shocks $\left(P_{t}^{x_{*}}, P_{t}^{z *}, A_{t}, Z_{t}\right)$ and on the allocation of labor in the commodity sector. Furthermore, if $\eta_{3}=0$ or if $\rho=1$, the previous equation shows that the correlation between $S_{t}$ and $P_{t}^{x *}$ will be negative, as in Table 2 . Moreover, in all of the numerical exercises that we have performed, the endogenous movements of $n_{t}^{x}$ when $\eta_{3}>0$ and $\rho<1$ never change the negative correlation between $S_{t}$ and $P_{t}^{x *}$. Therefore, a small open economy that follows inflation targeting will experience fluctuations on the exchange rate that depend on movements in commodity prices and productivity shocks, as well as on the properties of the input-output matrix (the parameters $\left.\rho, \eta^{1}, \eta^{2}, \eta^{3}\right)$.

\section{Foreign Sector and Feasibility}

We assume an isoelastic foreign demand for the home final good of the form

$$
C_{t}^{h *}=\left(K_{t}^{*}\right)^{\gamma}\left(P_{t}^{h *}\right)^{-\gamma}
$$

where $\gamma>1, P_{t}^{h *}$ is the foreign currency price of the home final good, and $K_{t}^{*}$ is a stochastic process that transforms units of foreign currency into domestic consumption goods. ${ }^{17}$

The government imposes a tax $\left(1+\tau_{t}^{h}\right)$ on final goods exported to the rest of the world and a tariff $\left(1+\tau_{t}^{f}\right)$ on final good imports. The law of one price

\footnotetext{
${ }^{17} \mathrm{We}$ allow for the final goods to be traded, so a particular case of our model (the one with $A=0$ and $\eta_{1}=\eta_{2}=0$ ) without commodities is the one analyzed in the small open economy NK literature. But none of the results hinges on this feature.
} 
on domestic and foreign final goods then requires

$$
\begin{aligned}
& P_{t}^{h}\left(1+\tau_{t}^{h}\right)=S_{t} P_{t}^{h *} \\
& P_{t}^{f}=S_{t} P_{t}^{f *}\left(1+\tau_{t}^{f}\right),
\end{aligned}
$$

where $P_{t}^{f *}$ is the foreign currency price of the foreign final good.

Net exports measured in foreign currency are given by

$$
m_{t}^{*}=P_{t}^{h *} C_{t}^{h *}-P_{t}^{f *} C_{t}^{f}+P_{t}^{x *}\left[X_{t}-\int_{0}^{1} x_{i t} d i\right]-P_{t}^{z *} \int_{0}^{1} z_{i t} d i .
$$

Thus, the net foreign assets of the country, denoted by $B_{t, t+1}^{*}$, evolve according to

$$
B_{t-1, t}^{*}+m_{t}^{*}=E_{t} B_{t, t+1}^{*} Q_{t, t+1}^{*} .
$$

Solving this equation from period 0 forward, and assuming zero initial foreign assets, gives the economy foreign sector feasibility constraint measured in foreign currency at time 0 :

$$
E_{0} \sum_{t=0}^{\infty} Q_{0, t}^{*} m_{t}^{*}=0
$$

In addition, market clearing in domestic final goods requires

$$
Y_{t}^{h}=C_{t}^{h}+C_{t}^{h *}+G_{t}^{h}
$$

and labor market feasibility is given by

$$
N_{t}=\int_{0}^{1} n_{i t}^{y} d i+n_{t}^{x}
$$

\section{The Ramsey Problem}

We assume that the government is able to commit to a particular policy chosen at the initial period and never deviates from it.

To characterize the optimal policy, the Ramsey taxation literature finds necessary and sufficient conditions that an allocation has to satisfy to be implementable as an equilibrium (Lucas and Stokey, 1983; Chari and Kehoe, 1999). In our model, however, these sufficient conditions cannot be characterized in terms of the allocation alone. ${ }^{18}$ The constraints imposed by the price setting restrictions on the equilibrium allocation make the

\footnotetext{
${ }^{18}$ This is similar to the closed economy version of Correia, Nicolini, and Teles (2008).
} 
equilibrium set a difficult object to analyze. We thus follow a different approach and define a relaxed set of allocations that contains the set of equilibrium allocations for any degree of price stickiness $\alpha$. The relaxed set is defined in terms of necessary conditions that any equilibrium allocation must satisfy.

Proposition 1 Given domestic currency prices $P_{i t}^{h}$, any equilibrium allocation of the economy with commodities satisfies

$$
\begin{aligned}
& E_{0} \sum_{t=0}^{\infty} \beta^{t}\left[U_{C}\left(C_{t}, N_{t}\right) H\left(C_{t}^{h}, C_{t}^{f}\right)+U_{N}\left(C_{t}, N_{t}\right) N_{t}\right]=0, \\
& E_{0} \sum_{t=0}^{\infty} Q_{0, t}^{*}\left[K_{t}^{*}\left(C_{t}^{h *}\right)^{\frac{\gamma-1}{\gamma}}-P_{t}^{f *} C_{t}^{f}+P_{t}^{x *} A_{t}\left(n_{t}^{x}\right)^{\rho}\right. \\
& \left.\quad-\left(\frac{1-\eta_{3}}{\eta_{3}}\right) P_{t}^{x *} \rho A_{t}\left(n_{t}^{x}\right)^{\rho-1}\left(N_{t}-n_{t}^{x}\right)\right]=0, \\
& \frac{Z_{t}}{\eta_{3}}\left(\rho A_{t}\left(n_{t}^{x}\right)^{\rho-1}\right)^{1-\eta_{3}}\left(P_{t}^{x *}\right)^{\eta_{2}}\left(P_{t}^{z *}\right)^{-\eta_{2}}\left(N_{t}-n_{t}^{x}\right)=D_{t}\left[C_{t}^{h}+C_{t}^{h *}+G_{t}^{h}\right],
\end{aligned}
$$

where

$$
D_{t}=\int_{0}^{1}\left(P_{i t}^{h} / P_{t}^{h}\right)^{-\theta} d i
$$

is an index of price dispersion across domestic final good firms. This index satisfies $D_{\mathrm{t}} \geq 1$ with equality if and only if $P_{i t}^{h}=P_{t}^{h}$ for all $i \in(0,1)$.

Proof In the Appendix.

Condition (26) summarizes the household's optimization problem, condition (27) is the foreign sector feasibility constraint, and condition (28) is market clearing in the market for home final goods.

Our strategy is to find the allocation that maximizes the household's utility among all allocation satisfying the conditions in Proposition 1. We call this the relaxed optimal allocation. In particular, we define the relaxed set of allocations as the set of allocations $\left\{C_{t}^{h}, C_{t}^{f}, C_{t}^{h *}, N_{t}, n_{t}^{x}\right\}$ such that conditions (26), (28), (27), and (29) hold for some prices $P_{t}^{h *}, P_{t}^{h}$, and $P_{i t}^{h}$ for $i \in(0,1)$, where $P_{t}^{h}$ and $P_{i t}^{h}$ also satisfy Equation (9).

The relaxed set of allocations imposes less restrictions on the allocation than the equilibrium set. In particular, the relaxed set allows for firm-specific prices $P_{i t}^{h}$, disregards the constraint imposed by the price setting restriction (equation (16)), and ignores the no-arbitrage condition (equation (3)). It then 
follows that any equilibrium allocation delivers utility no greater than that attained under the allocation that maximizes utility among allocations in the relaxed set. We next show, however, that - given the policy instruments we consider - the optimal allocation belongs to the relaxed set. Therefore, the relaxed optimal allocation is the best allocation among all equilibrium allocations.

Before finding the best allocation within the set of relaxed allocation, we prove that if, for any reason, the planner wishes - and is able - to impose $D_{t}=1$ for all $t$, so that the prices of all intermediate good producers are the same in any period, then any allocation that satisfies constraints (26), (27), and (28) is an equilibrium allocation.

Proposition 2 Suppose $P_{i 0}^{h}=P_{0}^{h}$ for all $i \in(0,1)$. Then, any allocation $\tilde{a}_{t}=\left\{\tilde{C}_{t}^{h}, \tilde{C}_{t}^{f}, \tilde{C}_{t}^{h}, \tilde{N}_{t}, \tilde{n}_{t}^{x}\right\}$ that belongs to the relaxed set of allocations described in Proposition 1 under the additional constraint $D_{t}=1$ can be implemented as an equilibrium with sticky prices. Moreover, in these equilibria, the prices of the home intermediate goods are constant and equal to $P_{i t}^{h}=P_{0}^{h}$ for all $t$ and all $i \in(0,1)$.

\section{Proof In the Appendix.}

To find the relaxed optimal allocation, we start by noting that it is optimal to set $D_{t}=1$ for all $t$. That is, the price of all intermediate good firms must be the same and equal to $P_{i t}^{h}=P_{t}^{h}$ for all $i \in(0,1)$. This is so because $D_{t}=1$ is the value that attains production efficiency. To see this, note that the term $D_{t}$ appears only in Equation (28). Given a level of output of home final goods (the left side of equation (28)), consumption of home final goods is maximized when $D_{t}=1$. In other words, the price frictions imply that, in equilibrium, otherwise identical firms may be setting different prices. If this is the case, the equilibrium does not exhibit production efficiency and the allocation lies inside the production possibility frontier. As it turns out, production efficiency is a property of the second best, as has been pointed by Diamond and Mirrlees (1971).

But $D_{t}=1$ can occur only if monetary policy is able to implement constant intermediate good prices. That is, monetary policy must be such that firms that are able to reoptimize prices will choose to set the same constant price in every period. For the rest of this section, we consider the relaxed Ramsey problem under constant prices.

It is convenient to define the distorted utility function

$$
V(C, N ; \lambda) \equiv U(C, N)+\lambda\left(U_{C}(C, N) H\left(C^{h}, C^{f}\right)+U_{N}(C, N) N\right)
$$

where $\lambda$ is the Lagrange multiplier on the implementability constraint (26) and $C=H\left(C^{h}, C^{f}\right)$. The distorted utility function includes the contribution of constraint (26) to utility. 
The Lagrangian of the relaxed Ramsey problem is to choose $N_{t}, C_{t}^{h}, C_{t}^{f}, n_{t}^{x}, C_{t}^{h_{*}}$ so as to

$$
\begin{gathered}
\max E_{0} \sum_{t=0}^{\infty} \beta^{t} V\left(C_{t}, N_{t} ; \lambda\right) \\
+E_{0} \sum_{t=0}^{\infty} \varphi_{t}\left[\frac{Z_{t}}{\eta_{3}}\left(\rho A_{t}\left(n_{t}^{x}\right)^{\rho-1}\right)^{1-\eta_{3}}\left(P_{t}^{x *}\right)^{\eta_{2}}\left(P_{t}^{z *}\right)^{-\eta_{2}}\left(N_{t}-n_{t}^{x}\right)\right. \\
\left.\quad-C_{t}^{h}-C_{t}^{h *}-G_{t}^{h}\right] \\
+\zeta E_{0} \sum_{t=0}^{\infty} Q_{0, t}^{*}\left[K_{t}^{*}\left(C_{t}^{h *}\right)^{\frac{\gamma-1}{\gamma}}-P_{t}^{f *} C_{t}^{f}+P_{t}^{x *} A_{t}\left(n_{t}^{x}\right)^{\rho}\right. \\
\left.\quad-\left(\frac{1-\eta_{3}}{\eta_{3}}\right) P_{t}^{x *} \rho A_{t}\left(n_{t}^{x}\right)^{\rho-1}\left(N_{t}-n_{t}^{x}\right)\right],
\end{gathered}
$$

where $\varphi_{t}$ is the Lagrange multiplier on Equation (28) and $\zeta$ is the multiplier on the foreign sector feasibility constraint (23).

After some algebra, we can write the necessary conditions for an optimum as

$$
\begin{aligned}
& \beta^{t} V_{C}\left(C_{t}, N_{t} ; \lambda\right) H_{C^{h}}\left(C_{t}^{h}, C_{t}^{f}\right)=\varphi_{t} \\
& \beta^{t} V_{C}\left(C_{t}, N_{t} ; \lambda\right) H_{C^{f}}\left(C_{t}^{h}, C_{t}^{f}\right)=\zeta Q_{0, t}^{*} P_{t}^{f *} \\
& -\beta^{t} V_{N}\left(C_{t}, N_{t} ; \lambda\right)=\zeta Q_{0, t}^{*} P_{t}^{x *} \rho A_{t}\left(n_{t}^{x}\right)^{\rho-1} \\
& \varphi_{t}=\zeta Q_{0, t}^{*} M C_{t}^{*} \\
& \varphi_{t}=\frac{\gamma-1}{\gamma} \zeta Q_{0, t}^{*} K_{t}^{*}\left(C_{t}^{h *}\right)^{\frac{-1}{\gamma}} .
\end{aligned}
$$

Note that the condition with respect to labor resembles the condition with respect to the foreign consumption aggregate. By dividing both equations, we obtain the following relationship:

$$
-\frac{V_{N}\left(C_{t}^{h}, C_{t}^{f}, N_{t} ; \lambda\right)}{V_{C^{f}}\left(C_{t}^{h}, C_{t}^{f}, N_{t} ; \lambda\right)}=\frac{P_{t}^{* *}}{P_{t}^{f *}} \rho A_{t}\left(n_{t}^{x}\right)^{\rho-1},
$$

so the marginal rate of substitution between labor and the foreign consumption aggregate (using the Ramsey planner preferences) is equalized to the price of the commodity relative to that of the foreign final good adjusted by the local productivity of labor in the production of the 
commodity. Thus, the presence of commodities implies that labor effectively becomes a traded good and terms-of-trade shocks directly affect local costs, a key determinant of domestic pricing decisions.

Given that the aggregator $H(\cdot)$ is constant returns to scale, by the Diamond and Mirrlees (1971) homogeneous taxation result, the margin between domestic and foreign consumption will not be distorted. In addition, as the elasticity of demand of intermediate goods is constant, the optimal mark-up is constant as well. To see this, use Equtions (30), (31), and (33) to obtain

$$
\frac{H_{C^{h}}\left(C_{t}^{h}, C_{t}^{f}\right)}{H_{C^{f}}\left(C_{t}^{h}, C_{t}^{f}\right)}=\frac{M C_{t}^{*}}{P_{t}^{f *}} .
$$

Likewise, using Equations (5), (20), and the pricing equations (under price stability) for intermediate good firms gives

$$
\frac{H_{C^{h}}\left(C_{t}^{h}, C_{t}^{f}\right)}{H_{C^{f}}\left(C_{t}^{h}, C_{t}^{f}\right)}=\frac{\theta}{\theta-1} \frac{M C_{t}^{*}}{1+\tau_{t}^{f}} \frac{P_{t}^{f *}}{P^{*}}
$$

Comparing these equations, one finds that the optimal import tariff is constant and equal to

$$
1+\tau_{t}^{f}=\frac{\theta}{\theta-1} .
$$

Likewise, conditions (19), (20), (33), (34), and the pricing equation of intermediate good firms imply that the optimal tax on exports satisfies

$$
1+\tau_{t}^{h}=\frac{\gamma}{\gamma-1} \frac{\theta-1}{\theta}
$$

The first equation implies that the optimal tariff on the final foreign goods, $\tau_{t}^{f}$, is equal to the local mark-up that domestic producers impose on domestic final goods. In this way, the relative price that domestic consumers face is equal to the marginal rate of transformation. The second equation implies that the export tax $\tau_{t}^{h}$ corrects the local mark-up chosen by the domestic monopolists to make foreign consumers face the optimal mark-up. Note that neither tax needs to be time or state dependent.

As price stability is a feature of the second best, the nominal exchange rate must move so as to stabilize domestic marginal costs, as discussed above, according to

$$
S_{t}=\frac{1}{M C} \frac{Z_{t}}{\left(P_{t}^{x *}\right)^{1-\eta_{2}}\left(P_{t}^{z *}\right)^{\eta_{2}}\left(\rho A_{t}\left(n_{t}^{x}\right)^{\rho-1}\right)^{\eta_{3}}} .
$$

For example, in the particular case of $\eta_{3}=0$, and ignoring productivity shocks $\left(A_{t}=A, Z_{t}=Z\right)$, then

$$
\ln S_{t}=k-\left(1-\eta_{2}\right) \ln P_{t}^{x *}-\eta_{2} \ln P_{t}^{z *},
$$


where $k$ is an irrelevant constant. Thus,

$$
\begin{aligned}
\operatorname{Var}\left(\ln S_{t}\right)= & \left(1-\eta_{2}\right)^{2} \operatorname{Var}\left(\ln P_{t}^{x *}\right)+\eta_{2}^{2} \operatorname{Var}\left(\ln P_{t}^{z *}\right) \\
& +2\left(1-\eta_{2}\right) \eta_{2} \operatorname{Cov}\left(\ln P_{t}^{z *}, \ln P_{t}^{x *}\right)
\end{aligned}
$$

which implies that the larger the volatility of the price of the exportable commodity, the larger the volatility of the nominal exchange rate, and

$$
\operatorname{Cov}\left(\ln S_{t}, \ln P_{t}^{x *}\right)=-\left(1-\eta_{2}\right) \operatorname{Var}\left(\ln P_{t}^{x *}\right)-\eta_{2} \operatorname{Cov}\left(\ln P_{t}^{z *}, \ln P_{t}^{x *}\right),
$$

so, as long as $\operatorname{Cov}\left(\ln P_{t}^{z *}, \ln P_{t}^{x *}\right)>0$ as is the case with commodities in the data, the covariance (and therefore the correlation) between the nominal exchange rate and the price of the exportable commodity will be negative, as in the data.

At this level of generality, little can be said regarding labor income taxes. Optimal labor income taxes fluctuate to make sure that the Ramsey allocation also satisfies the intratemporal equilibrium condition

$$
\frac{U_{C}\left(C_{t}, N_{t}\right) H_{C^{h}}\left(C_{t}^{h}, C_{t}^{f}\right)}{-U_{N}\left(C_{t}, N_{t}\right)}=\frac{P_{t}^{h}}{W_{t}\left(1-\tau_{t}^{n}\right)} .
$$

Likewise, taxes on the return on foreign assets move over time so that the Ramsey allocation satisfies the intertemporal equilibrium condition

$$
\frac{U_{C}\left(C_{t}, N_{t}\right) H_{C^{h}}\left(C_{t}^{h}, C_{t}^{f}\right)}{P_{t}^{h}}=\frac{\beta S_{t+1}}{Q_{t, t+1}^{*}\left(1+\tau_{t+1}^{*}\right) S_{t}} \frac{U_{C}\left(C_{t+1}, N_{t+1}\right) H_{C^{h}}\left(C_{t+1}^{h}, C_{t+1}^{f}\right)}{P_{t+1}^{h}} .
$$

In a model with no commodities or taxes on capital flows, the last equation is satisfied by appropriate fluctuations in the nominal exchange rate. In the model with commodities, however, the nominal exchange rate moves to stabilize local marginal costs. Therefore, it is necessary to endow the government with another instrument to make sure that the Ramsey allocation also satisfies the Euler equation of the households. In this paper, we consider taxes on capital flows; consumption taxes, however, could also be used for this purpose.

As we mentioned above, this result requires flexible tax instruments $\tau_{t}^{n}, \tau_{t}^{*}$. In the next proposition, however, we show that for a family of preferences, optimal tax rates are constant across states and periods. Interestingly enough, these are the preferences that have been widely used in the NK small open economy literature.

Proposition 3 Consider a utility function of the form

$$
U(C, N, m)=\frac{C^{1-\sigma}}{1-\sigma}-\kappa \frac{N^{1+\psi}}{1+\psi}, \quad \sigma, \psi, \kappa>0
$$


Then, the optimal policy sets a constant labor tax, $\tau_{\mathrm{t}}^{\mathrm{n}}=\tau^{\mathrm{n}}$, and zero taxes on capital flows, $\tau_{\mathrm{t}}{ }^{*}=0$, across dates and states of nature. ${ }^{19}$

Proof In the Appendix.

Thus, as long as preferences can be well approximated by the ones specified in Proposition 3, price stability is optimal and no case can be made for "fear of floating." Note, also, that this result holds for any specification of the aggregator $C=H\left(C^{h}, C^{f}\right)$. In the next section, we numerically solve the model to evaluate how well it can reproduce the moments in Table 2.

\section{Numerical Experiment}

This section provides a quantitative exploration of the model. Though we motivate most of the parameters we pick using existing empirical literature, our purpose is not to provide a serious calibration for a particular country. Rather, our aim is to illustrate that there are reasonable parametrizations such that, under the optimal policy, the model is able to produce a volatility of the nominal exchange rate and a correlation between the nominal exchange rate and the commodity price similar to those observed in the data. In particular, given that the cases of Chile and Norway have been inspirational for us, we want to consider parameters such that the labor share on the production of commodities is very low and that the export share of the production of the commodity is very large. A full calibration exercise requires a model flexible enough to attend to the many details of the particular small open economies we consider; this is beyond the scope of this paper and we leave it for further research.

Each period in the model corresponds to one quarter. We consider the following preferences:

$$
U\left(C_{t}^{h}, C_{t}^{f}, N_{t}\right)=\omega \log C_{t}^{h}+(1-\omega) \log C_{t}^{f}-\kappa \frac{N_{t}^{1+\psi}}{1+\psi},
$$

which correspond to those in Proposition 3 when $\sigma \rightarrow 1$. Thus, in this example, optimal labor taxes are state and time independent and taxes on capital flows are zero. We calibrate the preference parameters as follows. The discount factor $\beta$ is set at 0.95 on an annualized basis; the parameter $\omega$, the share of the home final good in the utility function, is 0.6 ; the parameter $\kappa=11$, which delivers an average labor supply of about 0.3 across simulations; and the parameter $\psi$ is set to one, which corresponds to a unitary Frisch elasticity of labor supply. This number is between the micro and macro estimates of the Frisch elasticity found in the literature (Chetty and others, 2011).

\footnotetext{
${ }^{19}$ The result of zero taxes on capital flows is more general. A utility function of the form $C^{1-\sigma} /(1-\sigma)-V(N)$ for any function $V(N)$ implies zero taxes on capital flows. The proof is identical to that of Proposition 3.
} 
The model has four exogenous state variables $\left\{P_{t}^{x *}, P_{t}^{z *}, Z_{t}, A_{t}\right\}$. We assume the following stochastic processes for the shocks:

$$
\begin{aligned}
\log \left(P_{t}^{x *} / \bar{P}^{x *}\right) & =b^{x} \log \left(P_{t-1}^{x *} / \bar{P}^{x *}\right)+\varepsilon_{t}^{x}, \\
\log \left(P_{t}^{z *} / \bar{P}^{z *}\right) & =b^{z} \log \left(P_{t-1}^{z *} / \bar{P}^{z *}\right)+\varepsilon_{t}^{z}, \\
\log \left(A_{t} / \bar{A}\right) & =b^{A} \log \left(A_{t-1} / \bar{A}\right)+\varepsilon_{t}^{A}, \\
\log \left(Z_{t} / \bar{Z}\right) & =b^{Z} \log \left(Z_{t-1} / \bar{Z}\right)+\varepsilon_{t}^{Z},
\end{aligned}
$$

where, for $j=x, z, A, Z, \varepsilon_{t}^{j}$ is normally distributed with mean 0 and standard deviation $\sigma_{\varepsilon^{j}}$. The innovations $\varepsilon_{t}^{i}, \varepsilon_{t}^{j}$ could be contemporaneously correlated for $j \neq i$. Consider first the process for the international price of the exportable commodity, $P_{t}^{x *}$. We calibrate the parameters $b^{x}$ and $\sigma_{\varepsilon^{x}}$ by running a firstorder autoregression on quarterly HP-filtered data on the logarithm of the price of oil over the period 1991:Q1-2012:Q4. We obtain $b^{x}=0.63$ and $\sigma_{\varepsilon^{x}}=0.15$. To calibrate $\bar{P}^{x}$, we note that, under the invariant distribution, $E\left(P_{t}^{x *}\right)=\bar{P} \exp \left(0.5 \sigma_{\varepsilon^{x}}^{2}\right)$. We next use the estimated value for $\sigma_{\varepsilon^{x}}^{2}$ and the average of the price of oil (38.7 Jan. 2000 U.S. dollars) into this expression and obtain $\bar{P}=36.7$. We use the same process for the price of the importable commodity. Finally, for the technology shocks, we assume $b^{A}=b^{Z}=0.96$, $\sigma_{\varepsilon^{A}}=\sigma_{\varepsilon^{Z}}=0.08$, and $\bar{A}=\bar{Z}=1$.

The persistence of the technology shocks is similar to that estimated in the small open economy literature (for example, Neumeyer and Perri, 2005; Aguiar and Gopinath, 2007). The volatility, however, is larger-about twice as large as the one they use. We choose a larger volatility for two reasons. First and foremost, the volatility has been pushed up so as to match the numbers in Table 2. This is the free parameter we use. Second, ours is a multisector model, while these authors consider a one-sector model. Owing to diversification forces, it is reasonable to choose more volatile sectorial productivity shocks as the economy becomes more disaggregated. Had we used a number for the volatility used by Neumeyer and Perri (2005), the model would deliver only 70 percent of the volatility on the nominal exchange rate and would overpredict the correlation by 15 percent.

Even though there are four exogenous shocks, in the Ramsey allocation the shocks $P_{t}^{z *}$ and $Z_{t}$ come bundled as $\left(P_{t}^{z *}\right)^{\eta_{2}} / Z_{t}$. Therefore, these two state variables collapse to one, labeled $\tilde{P}_{t}^{z}=\left(P_{t}^{z *}\right)^{\eta_{2}} / Z_{t}$. By a standard result in timeseries analysis, it then follows that $\log \tilde{P}_{t}^{z}$ is distributed as an $\operatorname{ARMA}(2,1)$ process. Thus, the state of the economy at time $t$ is summarized by the vector $\left(\log P_{t}^{x *}, \log \tilde{P}_{t}^{z *}, \log A_{t}\right)$. Finally, we also assume that the correlation between the innovation in the process for the commodity price $\log P_{t}^{x_{*}}$ and the innovation of the $\operatorname{ARMA}(2,1)$ process for the bundled shock $\log \tilde{P}_{t}^{z *}$ is 0.6 . This number is in line with the correlation between some of the prices depicted in Figure 1.

We set the remaining parameters of the model as follows. We choose a small contribution of labor in the commodity sector $x, \rho=0.1$, consistent 
with the observation that commodities are not too labor intensive. Regarding the intermediate goods sector, we assume a small share of the commodity $x$ in production, of just $\eta_{1}=0.08$, but a relatively large share of importable commodities, of $\eta_{2}=0.35$. The labor share in the intermediate goods sector is, therefore, $\eta_{3}=0.57$. With this parameterization, 80 percent of the production of the home commodity is exported, and the rest is used in the production of intermediate goods. Regarding the foreign demand of the home final good, we assume $\gamma=2$ and $K^{*}=5{ }^{20}$ Finally, we set $P_{t}^{f_{*}}=1$ for all $t$, and the nominal price in the intermediate good sector is initialized at $P_{0}^{h}=50$ - this price remains fixed under the optimal policy. These parameters imply that the share of average distortionary government consumption-defined as government consumption minus the rent from the commodity sector - as a fraction of GDP is about 0.24.

Under the optimal policy, the first-order conditions from the Ramsey problem imply that the optimal allocation is a time-invariant function of the state vector $\left(\log P_{t}^{x *}, \log \tilde{P}_{t}^{z *}, \log A_{t}\right)$ and of the (constant) Lagrange multipliers $\lambda$ and $\zeta$. We solve the model numerically using a global solution method with a locally affine policy function. In particular, we choose a grid of 13 nodes for the three exogenous shocks. ${ }^{21}$ Given a guess for the multipliers $\lambda$ and $\zeta$, we solve the system of equations (30)-(34) at each grid point. We evaluate the solution at other points using trilinear interpolation. Given the proposed policy functions, we check whether the present value constraints (26) and (27) are satisfied at equality. To do this, we perform Monte Carlo simulations by drawing 1,000 histories of length 1,500 from the three exogenous shocks and evaluate the present value constraints using sample averages across the different histories. We use a nonlinear equation solver to find the parameters $\lambda$ and $\zeta$ such that Equations (26) and (27) hold at equality.

The proposed structure of the input-output matrix, together with processes for the exogenous shocks, is able to reproduce the volatility of the exchange rate and its correlation with the commodity price $P_{t}^{x *}$ displayed in Table 2. To compute these statistics, we run 5,000 simulations of length 1,100 by randomly drawing shocks according to the proposed stochastic processes and drop the first 100 observations from each history. We next compute the sample standard deviation of $\log S_{t}$ and the sample correlation of $\log S_{t}$ and $\log P_{t}^{x *}$ for each history and then take the average of these statistics across the 5,000 simulations (computing the median gives very similar results). The model delivers an average standard deviation of $\log S_{t}$ of 0.06 (with a standard error of 0.004 ) and an average correlation between $\log S_{t}$ and $\log P_{t}^{x *}$ of -0.8 (with a standard error of 0.024 ). The top panels of Figure 3 report the sample distribution of these two statistics across the 5,000 histories. The lower panels of Figure 3 report two typical histories of length

\footnotetext{
${ }^{20}$ This demand is assumed to be deterministic in our model, so these parameters are almost irrelevant.

${ }^{21}$ The nodes are chosen so that the grid partitions the real line into 14 intervals with the same probability under the invariant distribution of each shock. This implies that the grid is more densely populated near the mean of the invariant distribution.
} 
Figure 3. Results of the Monte Carlo Simulations
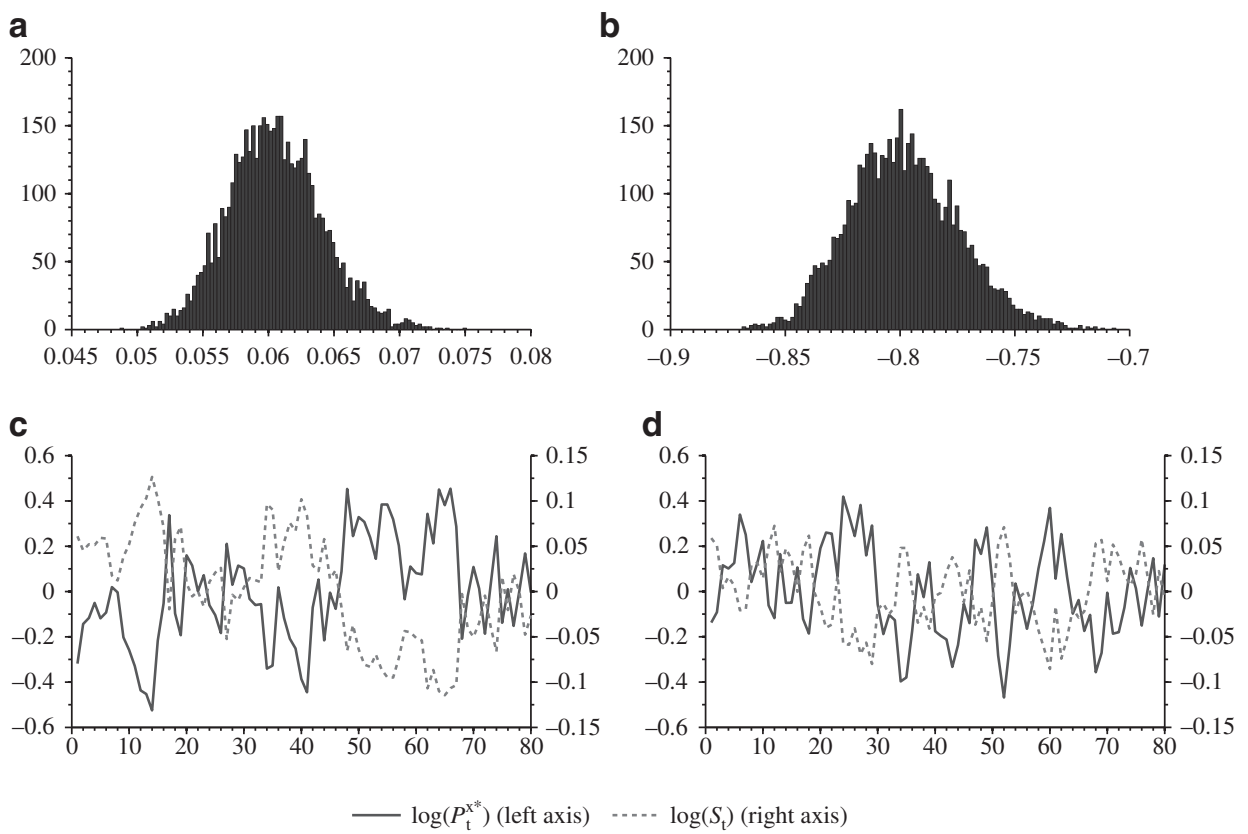

The top panels display histograms of the standard deviation of the logarithm of the exchange rate and the correlation between the logarithm of the exchange rate and the commodity price across simulations. The lower panels display two sample paths of the logarithm of exchange rates and commodity prices, both expressed as deviations from their means. (a) Histogram of standard deviation of $\log \left(S_{t}\right)$; (b) Histogram of correlation between $\log \left(S_{t}\right)$ and $\log \left(P_{t}^{x_{*}}\right)$; (c) History of $\log \left(P_{t}^{x *}\right)$ and $\log \left(S_{t}\right)$; (d) History of $\log \left(P_{t}^{x *}\right)$ and $\log \left(S_{t}\right)$.

80 (20 years) of the nominal exchange rate and the commodity price $P_{t}^{x *}$, both in natural logarithms and demeaned.

In summary, we find that there is a reasonable parametrization of the model that is able to reproduce the observed volatility of the nominal exchange rate and its correlation with commodity prices. To what extent the parametrization resembles an actual economy is an open question. That will probably require building a more elaborate model with physical capital and a deeper understanding of the input-output matrix of the economy to correctly capture the intersectoral linkages and, therefore, the transmission mechanism of monetary policy.

\section{Conclusions}

In this paper, we extended the by now standard open economy model with price frictions to consider international trade in commodities. We used the model to study optimal macroeconomic policy, in particular, the optimal response of policy to commodity price shocks. The model has the novel and attractive feature that it can reproduce the time-series properties of the 
nominal exchange rate that we observe in small open economies that follow inflation targeting, like Chile and Norway.

Contrary to what is standard in the NK literature, we jointly consider monetary, exchange rate, and fiscal policy. That is, we allow the planner to use fiscal instruments like tariffs, labor income taxes, and taxes on the return on foreign assets as well as monetary policy.

We show that if taxes can be made state and time dependent, the model implies that price stability is optimal. We also show that for the preferences used in the literature, the optimal taxes are indeed independent of the time period and the state, so for those preferences, even if taxes are not flexible instruments, price stability is optimal. Thus, the model rationalizes the optimality of inflation targeting and, as it is compatible with the observed nominal exchange rate volatility, it implies that interventions in the foreign exchange market are not warranted by the large observed swings in the nominal exchange rate.

We believe that our results may be interpreted in two different ways. On the one hand, if one is constrained by the NK tradition of treating monetary policy as flexible (can respond to the state) and fiscal policy as nonflexible (cannot respond to the state), the way to interpret our results depends on how seriously we are willing to take the preferences used in the literature. If we believe that they are a reasonable approximation to reality, then constant taxes and price stability characterize the optimal policy. And extreme volatility of the nominal - and real-exchange rate will be a feature of economies subject to very volatile terms of trade. In a sense, with those preferences, the restriction that fiscal policy is not flexible is inessential.

On the other hand, one may want to depart from the NK tradition, and embrace the Old Keynesian (OK) one. In effect, in a classic paper, Poole (1970) used an IS-LM model to study the optimality of fiscal and monetary policy. In that model - and in the other ones in that tradition - there was no asymmetric treatment of fiscal and monetary policy. There are important differences between the institutional arrangements in most modern economies that imply that there may be asymmetries, as the NK literature suggests. And it may well be the case that when stabilization policy is about nickels and dimes in welfare terms, as it is in models for closed economies and small shocks, like during the great moderation period, the debate over the flexibility of taxes is not relevant.

However, for economies that are subject to shocks - commodity pricesthat are five times more volatile than in developed economies, or for shocks like the ones experienced since 2008, the debate seems to be an important one. In this case, we believe that the OK tradition of jointly considering fiscal and monetary policy deserves attention. An important example can be found in the recent experience of Turkey, as forcefully explained by Governor Başçi in his conference participation. ${ }^{22}$

\footnotetext{
${ }^{22}$ See "Panel Speech at the Conference on 'Policy Responses to Commodity Price Movements'," April 7, 2012, www.tcmb.gov.tr/yeni/announce/2012/Baskan_IMF_Istanbul_ en.pdf.
} 


\section{APPENDIX}

\section{Proof of Proposition 1}

Condition (26) summarizes the household's behavior and follows from introducing Equations (5), (6), and (7) into Equation (4) evaluated at equality, and using that $H\left(C^{h}, C^{f}\right)$ is constant returns to scale. Integrating Equations (8), (14), and (15) over $\mathrm{i} \in(0,1)$ and rearranging gives

$$
\begin{aligned}
& \int_{0}^{1} x_{i t} d i=\frac{\eta_{1}}{Z_{t}}\left[\rho A_{t}\left(n_{t}^{x}\right)^{\rho-1}\right]^{\eta_{3}}\left(P_{t}^{x *}\right)^{-\eta_{2}}\left(P_{t}^{z *}\right)^{\eta_{2}} D_{t} Y_{t}^{h} \\
& \int_{0}^{1} z_{i t} d i=\frac{\eta_{2}}{Z_{t}}\left[\rho A_{t}\left(n_{t}^{x}\right)^{\rho-1}\right]^{\eta_{3}}\left(P_{t}^{x *}\right)^{1-\eta_{2}}\left(P_{t}^{z *}\right)^{\eta_{2}-1} D_{t} Y_{t}^{h} \\
& \int_{0}^{1} n_{i t}^{y} d i=\frac{\eta_{3}}{Z_{t}}\left[\rho A_{t}\left(n_{t}^{x}\right)^{\rho-1}\right]^{\eta_{3}-1}\left(P_{t}^{x *}\right)^{-\eta_{2}}\left(P_{t}^{z *}\right)^{\eta_{2}} D_{t} Y_{t}^{h},
\end{aligned}
$$

where $D_{t}$ is the index of price dispersion given by $D_{t}=\int_{0}^{1}\left(P_{i t}^{h} / P_{t}^{h}\right)^{-\theta} d i$.

Introducing Equation (A.3) into the labor market feasibility condition (equation (25)) gives

$$
N_{t}=n_{t}^{x}+\frac{\eta_{3}}{Z_{t}}\left[\rho A_{t}\left(n_{t}^{x}\right)^{\rho-1}\right]^{\eta_{3}-1}\left(P_{t}^{x *}\right)^{-\eta_{2}}\left(P_{t}^{z *}\right)^{\eta_{2}} D_{t} Y_{t}^{h} .
$$

Using this equation with Equation (24) gives condition (28). Next, using Equations (A.1) and (A.2) we can write

$$
P_{t}^{x *} \int_{0}^{1} x_{i t} d i+P_{t}^{z *} \int_{0}^{1} z_{i t} d i=\frac{1-\eta_{3}}{Z_{t}}\left[\rho A_{t}\left(n_{t}^{x}\right)^{\rho-1}\right]^{\eta_{3}}\left(P_{t}^{x *}\right)^{1-\eta_{2}}\left(P_{t}^{z *}\right)^{\eta_{2}} D_{t} Y_{t}^{h} .
$$

Using Equation (A.4) with the previous equation implies

$$
P_{t}^{x *} \int_{0}^{1} x_{i t} d i+P_{t}^{z *} \int_{0}^{1} z_{i t} d i=\left(\frac{1-\eta_{3}}{\eta_{3}}\right) P_{t}^{x *} \rho A_{t}\left(n_{t}^{x}\right)^{\rho-1}\left(N_{t}-n_{t}^{x}\right) .
$$

Inserting this last expression, Equations (10), and (19) into Equation (21), and the resulting expression into Equation (23), we obtain condition (27).

It remains to prove that $D_{t} \geq 1$, with equality if and only if $P_{i t}^{h}=P_{t}^{h}$ for all $i \in(0,1)$. Let $w_{i t}=\left(P_{i t}^{h}\right)^{1-\theta}$. It then follows that $\left(P_{i t}^{h}\right)^{-\theta}=w_{i t}^{\theta /(\theta-1)}$, which is a strictly convex function of $w_{i t}$. Therefore, Jensen's inequality implies

$$
\int_{0}^{1}\left(P_{i t}^{h}\right)^{-\theta} d i=\int_{0}^{1} w_{i t}^{\theta /(\theta-1)} d i \geq\left(\int_{0}^{1} w_{i t} d i\right)^{\frac{\theta}{\theta-1}}=\left(P_{t}^{h}\right)^{\theta}
$$

with strict equality if and only if $P_{i t}^{h}=P_{t}^{h}$ for all $i \in(0,1)$. In fact, $D_{t}=1$ holds if prices are equal for all $i \in(0,1)$ except for those in a set of Lebesgue measure zero. 


\section{Proof of Proposition 2}

We find a government policy and a price system that implements $\tilde{a}_{t}$ as an equilibrium allocation under the constraint $D_{t}=1$ for all $t$. Throughout the proof, all expressions are evaluated at the proposed allocation $\tilde{a}_{t}$. If $D_{t}=1$ for all $t$, all intermediate good firms must set the same price, so that $P_{\mathrm{t}}^{\mathrm{h}}=P_{i t}^{h}$ for all $t$. This can happen only if firms that are able to change prices choose not to do so. Therefore, prices at $t$ must depend, at most, on $t-1$ information. Iterating this argument backward implies that prices must satisfy $P_{i t}^{h}=P_{0}^{h}$ for all $i \in(0,1)$ and all $t$. As mentioned in the text, this implies that the marginal cost of intermediate good firms must be stabilized, so that the nominal exchange rate must satisfy

$$
S_{t}=\left(\frac{\theta-1}{\theta}\right) \frac{P_{0}^{h}}{M C_{t}^{*}}
$$

for all t. Equations (11) and (12) then determine the equilibrium nominal prices $W_{\mathrm{t}}, P_{\mathrm{t}}^{\mathrm{x}}$, and $P_{t}^{z}$. Moreover, given the allocation and the proposed prices, Equations (5) and (6) determine the nominal price $P_{t}^{f}$ and the labor tax $\tau_{t}^{n}$. Given the optimal allocation, the value for the nominal exchange rate, and the exogenous price $Q_{t, t+1}^{*}$, Equations (3) and (7) determine the bond prices $\mathrm{Q}_{t, t+1}$ and the tax on capital flows $\tau_{t}^{*}$ for all $t \geq 1$. At time $t=0$ we set $\tau_{0}^{*}=0$.

Given the allocation, the foreign price $P_{t}^{f_{*}}$, and the nominal prices obtained so far, Equations (19) and (20) determine the nominal price $P_{t}^{h *}$ and the trade taxes $\tau_{t}^{h}$ and $\tau_{t}^{f}$. Finally, we find the equilibrium allocation of bonds as follows. Without loss of generality we assume that households do not hold foreign bonds; then, iterating forward on the household's budget constraint at each time $t$ gives the equilibrium allocation of domestic bonds,

$$
B_{t-1, t}^{*}=E_{t} \sum_{s=0}^{\infty} Q_{t, t+s}\left(P_{0}^{h} C_{t+s}^{h}+P_{t+s}^{f} C_{t+s}^{f}-W_{t+s}\left(1-\tau_{t+s}^{n}\right) N_{t+s}\right) .
$$

Likewise, iterating forward on the foreign asset accumulation equation (22), one obtains the allocation of foreign bonds $B_{t-1, t}^{*}$ for all $t$ :

$$
E_{t} \sum_{s=0}^{\infty} Q_{t, t+s}^{*} m_{t+s}^{*}+B_{t-1, t}^{*}=0 .
$$

The proof is finished by noting that, given the prices and taxes obtained above, the proposed allocation satisfies all the equilibrium conditions of the model with sticky prices.

\section{Proof of Proposition 3}

The proposed preferences imply

$$
\begin{aligned}
V(C, N ; \lambda) & =\frac{C^{1-\sigma}}{1-\sigma}(1+\lambda(1-\sigma)) \\
& -\kappa \frac{N^{1+\psi}}{1+\psi}(1+\lambda(1+\psi)),
\end{aligned}
$$

and, thus,

$$
\begin{aligned}
& V_{C}(C, N ; \lambda)=(1+\lambda(1-\sigma)) U_{C}(C, N) \\
& V_{N}(C, N ; \lambda)=(1+\lambda(1+\psi)) U_{N}(C, N) .
\end{aligned}
$$


Using Equations (6), (11), and the pricing equation for domestic intermediate good firms gives

$$
\frac{-U_{N}\left(C_{t}, N_{t}\right)}{U_{C}\left(C_{t}, N_{t}\right) H_{C^{h}}\left(C_{t}^{h}, C_{t}^{f}\right)}=\frac{A_{t} \rho\left(n_{t}^{x}\right)^{\rho-1} P_{t}^{x *}}{\left(\frac{\theta}{\theta-1}\right) M C_{t}^{*}}\left(1-\tau_{t}^{n}\right) .
$$

The solution of the planner's problem can be written as

$$
\frac{-V_{N}\left(C_{t}, N_{t}\right)}{V_{C}\left(C_{t}, N_{t}\right) H_{C^{h}}\left(C_{t}^{h}, C_{t}^{f}\right)}=\frac{A_{t} \rho\left(n_{t}^{x}\right)^{\rho-1} P_{t}^{x *}}{M C_{t}^{*}} .
$$

Using the proposed functional form and rearranging implies a constant labor tax:

$$
1-\tau_{t}^{n}=\left(\frac{\theta}{\theta-1}\right) \frac{1+\lambda(1-\sigma)}{1+\lambda(1+\psi)} .
$$

The first order conditions from the planner's problem imply

$$
\frac{\beta V_{C}\left(C_{t+1}, N_{t+1} ; \lambda\right) H_{C^{h}}\left(C_{t+1}^{h}, C_{t+1}^{f}\right)}{V_{C}\left(C_{t}, N_{t} ; \lambda\right) H_{C^{h}}\left(C_{t}^{h}, C_{t}^{f}\right)}=Q_{t, t+1}^{*} \frac{M C_{t+1}^{*}}{M C_{t}^{*}} .
$$

The first-order conditions from the household's problem, the no-arbitrage constraint (equation (3)), and the pricing condition of intermediate good firms imply

$$
\beta \frac{U_{C}\left(C_{t+1}, N_{t+1}\right) H_{C^{h}}\left(C_{t+1}^{h}, C_{t+1}^{f}\right)}{U_{C}\left(C_{t}, N_{t}\right) H_{C^{h}}\left(C_{t}^{h}, C_{t}^{f}\right)}=Q_{t, t+1}^{*}\left(1+\tau_{t+1}^{*}\right) \frac{M C_{t+1}^{*}}{M C_{t}^{*}} .
$$

\begin{tabular}{|c|c|c|c|c|}
\hline & \multirow[t]{2}{*}{ Exchange Rate Volatility } & \multicolumn{3}{|c|}{ Correlation of Exchange Rate with } \\
\hline & & $\mathrm{CI}$ & $\mathrm{C} 2$ & $\mathrm{C} 3$ \\
\hline Australia & $8.3(1.1)$ & $-0.40(0.11)$ & $-0.54(0.19)$ & $-0.53(0.13)$ \\
\hline Brazil & $11.6(1.3)$ & $-0.16(0.24)$ & $-0.61(0.15)$ & $-0.65(0.08)$ \\
\hline Chile & $7.7(0.9)$ & $-0.82(0.06)$ & $-0.11(0.15)$ & - \\
\hline Iceland & $13.0(1.8)$ & $0.11(0.17)$ & $-0.62(0.10)$ & - \\
\hline New Zealand & $9.0(1.1)$ & $-0.51(0.19)$ & $-0.58(0.08)$ & $-0.61(0.09)$ \\
\hline Norway & $6.3(1.0)$ & $-0.68(0.17)$ & $0.02(0.14)$ & - \\
\hline Peru & $2.3(0.5)$ & $-0.42(0.18)$ & $-0.30(0.21)$ & $-0.04(0.17)$ \\
\hline
\end{tabular}

Dividing these expressions and using the proposed preference gives $\tau_{t+1}^{*}=0$ for all $t \geq 1$. The initial tax remains a free instrument; we set $\tau_{0}^{*}=0$.

\section{A.I. Stylized Facts for Exchange Rates and Commodity Prices}

Table A1. Exchange Rates and Commodity Prices in Selected Countries

This table shows summary statistics of the nominal exchange rate and commodity prices for a selected group of countries measured in January 2000 U.S. dollars. Data are at a quarterly frequency and transformed as percentage deviations from trend. Deviations from trend are computed by HP-filtering the logarithm of each series with a smoothing parameter of 1,600. GMMbased standard errors are reported in parentheses.

Table A1 provides additional evidence for the volatility of the nominal exchange rate and its correlation with main commodity exports for all the inflation targeters displayed in Table 1. 


\section{REFERENCES}

Adao, B., I. Correia, and P. Teles, 2009, "On the Relevance of Exchange Rate Regimes for Stabilization Policy," Journal of Economic Theory, Vol. 144, No. 4, pp. $1468-88$.

Aguiar, M., and G. Gopinath, 2007, "Emerging Market Business Cycles: The Cycle Is the Trend," Journal of Political Economy, Vol. 115, No. 1, pp. 69-102.

Benigno, G., and P. Benigno, 2003, "Price Stability in Open Economies," Review of Economic Studies, Vol. 70, No. 4, pp. 743-64.

Burstein, A., M. Eichenbaum, and S. Rebelo, 2007, "Modeling Exchange Rate Passthrough After Large Devaluations," Journal of Monetary Economics, Vol. 54, No. 2, pp. 346-68.

Burstein, A., J. Neves, and S. Rebelo, 2003, "Distribution Costs and Real Exchange Rate Dynamics During Exchange-Rate-Based Stabilizations," Journal of Monetary Economics, Vol. 50, No. 6, pp. 1189-214.

Chari, V.V., L. Christiano, and P. Kehoe, 1996, "Optimality of the Friedman Rule in Economies with Distorting Taxes," Journal of Monetary Economics, Vol. 37, Nos. 2-3, pp. 203-23.

Chari, V.V., and P. Kehoe, 1999, "Optimal Fiscal and Monetary Policy," in Handbook of Macroeconomics, Vol. 1C, ed. by J. Taylor and M. Woodford (Amsterdam: North Holland).

Chen, Y., and K. Rogoff, 2003, "Commodity Currencies," Journal of International Economics, Vol. 60, No. 1, pp. 133-60.

Chetty, R., A. Guren, D. Manoli, and A. Weber, 2011, "Are Micro and Macro Labor Supply Elasticities Consistent? A Review of Evidence on the Intensive and Extensive Margins," American Economic Review: Papers \& Proceedings, Vol. 101, No. 3, pp. 471-5.

Correia, I., J. Nicolini, and P. Teles, 2008, "Optimal Fiscal and Monetary Policy: Equivalence Results," Journal of Political Economy, Vol. 116, No. 1, pp. 141-70.

Corsetti, G., and P. Pesenti, 2001, "Welfare and Macroeconomic Interdependence," Quarterly Journal of Economics, Vol. 116, No. 2, pp. 421-45.

_ 2005, "International Dimensions of Optimal Monetary Policy," Journal of Monetary Economics, Vol. 52, No. 2, pp. 281-305.

De Paoli, B., 2009, "Monetary Policy and Welfare in a Small Open Economy," Journal of International Economics, Vol. 77, No. 1, pp. 11-22.

Devereux, M., and C. Engel, 2003, "Monetary Policy in the Open Economy Revisited: Price Setting and Exchange-Rate Flexibility," Review of Economic Studies, Vol. 70, No. 4, pp. 765-83.

Diamond, P.A., and J.A. Mirrlees, 1971, "Optimal Taxation and Public Production: I-Production Efficiency," American Economic Review, Vol. 61, No. 1, pp. 8-27.

Duarte, M., and M. Obstfeld, 2008, "Monetary Policy in the Open Economy Revisited: The Case for Exchange-Rate Flexibility Restored," Journal of International Money and Finance, Vol. 27, No. 6, pp. 949-57.

Engel, C., 2001, "Optimal Exchange Rate Policy: The Influence of Price Setting and Asset Markets," Journal of Money, Credit and Banking, Vol. 33, No. 2, pp. 518-41.

Faia, E., and T. Monacelli, 2008, "Optimal Monetary Policy in a Small Open Economy with Home Bias," Journal of Money, Credit and Banking, Vol. 40, No. 4, pp. $721-50$. 
Farhi, E., G. Gopinath, and O. Itskhoki, 2011, "Fiscal Devaluations," NBER Working Paper 17662.

Ferrero, A., 2005, "Fiscal and Monetary Rules for a Currency Union," European Central Bank Working Paper 502.

Gali, J., and T. Monacelli, 2005, "Monetary Policy and Exchange Rate Volatility in a Small Open Economy," Review of Economic Studies, Vol. 72, No. 3, pp. 707-34.

Lucas Jr., R., and N. Stokey, 1983, "Optimal Fiscal and Monetary Policy in an Economy without Capital," Journal of Monetary Economics, Vol. 12, No. 1, pp. 55-93.

Neumeyer, P.A., and F. Perri, 2005, "Business Cycles in Emerging Economies: The Role of Interest Rates," Journal of Monetary Economics, Vol. 52, No. 2, pp. 345-80.

Obstfeld, M., and K. Rogoff, 1995, "Exchange Rate Dynamics Redux," Journal of Political Economy, Vol. 103, No. 3, pp. 624-60.

Obstfeld, M., and K.S. Rogoff, 1996, Foundations of International Macroeconomics (Cambridge, MA: MIT Press).

Obstfeld, M., and K. Rogoff, 2000, "New Directions for Stochastic Open Economy Models," Journal of International Economics, Vol. 50, No. 1, pp. 117-53.

Poole, W., 1970, "Optimal Choice of Monetary Policy Instruments in a Simple Stochastic Macro Model," Quarterly Journal of Economics, Vol. 84, No. 2, pp. 197-216.

Zhu, X., 1992, "Optimal Fiscal Policy in a Stochastic Growth Model," Journal of Economic Theory, Vol. 58, No. 2, pp. 250-89. 